\title{
Temporal distribution of water characteristics in the Miri estuary, east Malaysia
}

\begin{abstract}
This baseline study was carried out to investigate the physicochemical factors such as $\mathrm{pH}$, salinity, temperature, turbidity, total dissolved solids (TDS), total suspended solids and dissolved oxygen (DO), as well as nutrient (nitrate, phosphate, ammonium) concentrations and the level of heavy metals ( $\mathrm{Fe}, \mathrm{Zn}, \mathrm{Cu}, \mathrm{Mn}$ ) in the surface water of the Miri estuary at four sampling times based on the four seasons of Malaysia. Results indicated marked temporal differences in each of the water characteristics measured (except ammonium), where DO level (mean: $3.6 \mathrm{mg} / \mathrm{L}$ ) was found in a concern level. The principle component analysis (PCA) was applied to the hydrological and hydrochemical data set of the Miri estuary; results indicated that principle component 1 and principle component 2 explained 61.78 and 18.69\%, respectively, of the total variance in the data set. Besides, results of PCA also indicated that the factors for water characteristics variations were mainly related to TDS, salinity, and Fe. The data presented here will serve as benchmark information, especially to the agencies related to the formulation of suitable policy on water quality in such areas.
\end{abstract}

Keyword: Hydrological and hydrochemical factors; Malaysia; Miri estuary; Sarawak 